\title{
Spatial Heterogeneity of Coupling Coordination Development between Logistics and Economy in Central Plains of China
}

\author{
Guangliang Zhou, ${ }^{1}$ Congyu Zhao, ${ }^{1}$ Ming Wu, ${ }^{1,2}$ Yu Chen, ${ }^{1}$ and Fuli Zhou $\mathbb{C}^{1}$ \\ ${ }^{1}$ College of Economics and Management, Zhengzhou University of Light Industry, Zhengzhou, China \\ ${ }^{2}$ College of Economics and Management, Chongqing University, Chongqing, China \\ Correspondence should be addressed to Fuli Zhou; deepbreath329@outlook.com
}

Received 20 July 2021; Revised 16 December 2021; Accepted 24 December 2021; Published 21 January 2022

Academic Editor: Marcio Eisencraft

Copyright (c) 2022 Guangliang Zhou et al. This is an open access article distributed under the Creative Commons Attribution License, which permits unrestricted use, distribution, and reproduction in any medium, provided the original work is properly cited.

\begin{abstract}
The coupling of logistics and economy is of great significance for regional development. To promote the regional development of urban agglomeration in Central Plains of China, this paper attempts to study the spatial divergence of coupling development and the influential factors. The 30 urban cities in Central Plains of China have been regarded as the research objects. We develop an integrated framework to derive the coupling degree between logistics and economy in this region including linear weighting method, coupling coordination degree model, and exploratory spatial data analysis. The spatial pattern of the coupling coordination degree between logistics and economy is studied by the visualization evolution analysis. In addition, the GWR model is formulated to study the influential factors of regional coupling development. The results show that (1) the integrated development level of logistics industry and economy in the Central Plains City Cluster is low, and the development difference between regions is significant; (2) the overall coupling and coordination level of logistics industry and economy in the Central Plains City Cluster is not high and is at the stage of imminent disorder; in space, it presents a spatial pattern of "high in the center and low around"; (3) the coupling coordination degree around each region and city is a strong positive spatial correlation and agglomeration situation significantly; (4) the ranking of the influence degree of each driving factor from high to low is urbanization rate; science and technology level; education level; and population density.
\end{abstract}

\section{Introduction}

It has been mentioned that China's economy has shifted from the stage of high-speed growth to the stage of highquality development in the 19th Party Congress of China. It is an urgent problem to achieve high-quality development by transforming the development mode and economic structure. Logistics industry, as a productive service industry to ensure social production and life, plays an increasingly important role in optimizing the allocation of resources, reducing costs, and increasing efficiency in the process of logistics operation, which contributes to the supply-side structural reformation $[1,2]$.

The Central Plains City Cluster is one of the National City clusters in China, and the level of urbanization keeps an increasing trend in recent years. It has a three-dimensional integrated transportation network system with air, railway, and highway, which improves the transportation integration development. Therefore, it is important to explore and analyze the spatial pattern and influencing factors of the coupled and coordinated development of logistics industry and economy in the Central Plains City Cluster. This study is expected to help narrow the economic gap between regions. At the same time, it can promote the development of modern logistics and economy in the direction of high quality.

The academic research on the relationship between logistics industry and economic system has achieved fruitful results. The related research mainly focuses on the supply chain management [3-6], enterprise logistics performance 
[7-10], logistics infrastructure [11-14], green logistics [15-19], the interactive development of logistics industry, manufacturing industry and retail industry $[20,21]$, and the evaluation index of logistics industry development $[22,23]$. However, spatial pattern study of logistics industry and economic interaction coupling coordination is less, and the influence factor of these is much rarer.

In this paper, we take 30 prefecture-level cities in the Central Plains urban agglomeration as the research objects. The definition of it comes from the Central Plains Urban Agglomeration Development Plan approved by the State Council of the PRC. These cities are located in five provinces, namely, Henan, Hebei, Shandong, Shanxi, and Anhui. Among them, Zhengzhou, Kaifeng, Luoyang, Pingdingshan, Xinxiang, Jiaozuo, Xuchang, Luohe, Jiyuan, Hebi, Shangqiu, Zhoukou, Jincheng, and Bozhou city of Anhui Province are the core development zones. Besides, a geographically weighted regression (GWR) model, a spatial analysis technique widely used in geography and related disciplines of spatial pattern analysis, is developed to reveal the spatial heterogeneity of the influencing factors on the mechanism of the coupling and coordination degree of the two systems. The paper aims at providing a reference basis for both promoting high-quality development of the economy and logistics industry and assisting to achieve the coordinated development of the region.

\section{Coupling Coordination Mechanism between Logistics and Economy}

As two complex social systems, the logistics industry and the economy influence each other, depend on each other, and have a coupling relationship [24]. On the one hand, the development of national economy determines the development degree of logistics industry, which can affect the future growth track of logistics industry; on the other hand, the development of logistics industry will also make the regional national economy profoundly changed [25-27]. As a basic industry of national economy, the logistics industry has strong industrial relevance and involves many fields. It plays an important role in promoting economic development; on the other hand, stable and rapid development of economy is the support and guarantee of logistics industry. Only the coordinated development of the logistics industry and the national economy can ensure the continuous improvement of resource utilization and the sustainable utilization of logistics hub, logistics infrastructure, logistics distribution tools, human capital, and other elements [28-30].

2.1. The Role of Logistics Industry in Promoting the Economy. Logistics industry plays an important role in promoting the adjustment of industrial structure, which can change the mode of economic development and improve core competitiveness of industry $[29,31-33]$. Klaus believes that with the acceleration of globalization, logistics expenditure in the region has obvious positive relationship with regional wealth [28]. Logistics industry has become a condition to enhance regional wealth. The role of logistics industry in promoting the economy is mainly reflected in three aspects: promoting the transformation and upgrading of related industries, improving the efficiency of resource allocation, and enhancing regional innovation capacity [1, 34]. Firstly, the scale of development of the logistics industry continues to expand in the process of continuous extension of the logistics industry chain upstream and downstream. Relevant supporting industries are attracted to form industrial clusters. The scale effect and agglomeration effect of industrial clusters not only promote the development of logistics industry, but also promote the development of related industries. Secondly, the logistics industry is developing and growing. The gradual improvement of logistics park, storage platform, information platform, and other infrastructure not only supports the normal operation of logistics enterprises, but also provides convenience for other economic activities and reduces the cost due to time and distance. Lindsey pointed out logistics industry that the integrated supply chain formed by logistics facilities and regional freight hubs can play a great driving role in the development of global industry from the perspective of globalization [35]. Thirdly, the development of logistics industry contributes to the more frequent and closer cooperation and communication among crossregional manufacturers, suppliers, retailers, and users [36-38]. And the circulation speed of production factors such as human, capital, and technology is accelerated in this process, which can easily promote the creation of new growth poles, so as to provide conditions for innovation and development and help the development of high-quality economic. With the process of global economic integration and the increasing degree of industrial competition, as one of the important basic industries, the development of logistics industry plays an important role in deepening the division of labor, effectively improving the allocation of resources, improving the production efficiency of manufacturing industry, and promoting the coordinated development of regional economy [39].

\subsection{The Role of the Economy in Supporting the Logistics} Industry. The supporting effect of economy on logistics industry is mainly reflected in three aspects. Specifically, it includes in the provision of financial and technical support, the improvement of infrastructure, and the expansion of demand scale. Firstly, the links between industries have become stronger with the rapid growth of regional economy. At the same time, the level of openness to the outside world is improving. More active economic exchanges have been generated. In this process, the rapid flow of various factors of production has become more common, where the advanced knowledge, management concept, and professional talents promote the development of logistics industry [38].

Secondly, with the rapid development of the regional economy, the government investment in urban and rural transportation, information platforms, production equipment, warehousing, and other infrastructure gradually increases. Gradually, the continuous improvement of network communication and the logistics park is very helpful to form 
a complete socialized service system and logistics network system of logistics industry. The market space for the development of logistics industry is wider.

Thirdly, the higher the degree of economic development of a region, the more active the economic activities of various industries and economic sectors are. In addition, the degree of openness to the outside world will also be higher. A large number of trade activities are brought by the inter-regional connectivity, which promotes the development of the logistics industry. The development status of logistics industry in China shows that the more developed the regional economy is, the more active the regional manufacturing industry and trade industry are, the higher the demand for logistics is, and the better the development foundation and space of logistics industry are. The interactive mechanism between logistics industry and regional economy is found in Table 1 and Figure 1.

\section{Research Methods and Data Sources}

\subsection{Research Methodology}

3.1.1. Linear Weighting Method. In the comprehensive evaluation index system, due to the different roles and influence of each indicator, it is necessary to assign weights to each indicator according to its importance. Therefore, this paper first adopts the "minimum-maximum standard method" to process the data and eliminate the influence of the dimension of each indicator. Then, we use the "coefficient of variation method" to objectively determine the index weights and then build a comprehensive evaluation model of logistics industry and economic level. The formula is as follows [40]:

$$
\begin{aligned}
& f(x)=\sum_{j=1}^{n} \alpha_{j} \cdot x_{j}, \\
& g(y)=\sum_{j=1}^{n} \beta_{j} \cdot y_{j},
\end{aligned}
$$

where $f(x)$ and $g(y)$ are the index values indicating the development level of logistics industry and comprehensive economy level, respectively; $\alpha_{j}$ and $\beta_{j}$ are the weights of $i$ indexes of logistics industry and economy subsystems, respectively; and $y_{j}$ and $x_{j}$ are the values of each index of the two systems after standardization of the original data, respectively.

\subsubsection{Coupling Coordination Degree Model. The coupling is} a term in physics that refers to the phenomenon when two or more systems achieve coordination through interaction and mutual influence, and the coordination degree is used to measure the level of harmony and compatibility in the development of systems [41].

In recent years, coupled coordination degree (CCD) model has been widely used in many countries. Some scholars have used the coupled coordination model to analyze the coupling coordination of cities in other countries. For example, Mateusz Tomal [42] used the coupled coordination model to analyze whether the change process of the local development dimension of Polish cities from 2003 to 2019 was coordinated. Under the concept of sustainable development, six aspects of economy, population, housing, society, infrastructure, and environment are studied. The results show that the development of most Polish cities is unbalanced and unsustainable. Dong and Zhang et al. [43] combined entropy method and coupling coordination degree model to analyze urbanization and ecological environment in Mongolia from 2000 to 2016 and explored the coupling relationship between the two. The results show that the coupling coordination degree of Mongolian urbanization and ecological environment is in a serious unbalanced development stage. According to the research results, mode of the six-layer ecological city construction is proposed to provide scientific support for the sustainable development of Mongolian urbanization.

At present, the research fields using coupling coordination degree model in China mainly focus on provinces $[44,45]$, regions [46, 47], and industries [11, 40, 48], such as urbanization and logistics industry [27, 29, 43, 45], urban and rural economic development and ecological environment $[47,49]$, economic growth and environmental pollution $[50,51]$, pharmaceutical manufacturing industry and regional economy $[20,44,47,52]$, the innovation drive with high quality and economic development $[53,54]$, the sustainable development of regional economy $[55,56]$, science and technology innovation [57, 58], integrated transportation and logistics industry and financial industry $[29,35]$, rural revitalization and new type of urbanization $[43,45,59]$, the logistics industry and the new urbanization $[45,60]$, and so on. In addition to this method often used to study coupling coordination degree of two systems, there are also some studies of three systems, such as the coordinated development of economy, society, environment $[27,61]$ and tourism, urbanization, urban ecological environment $[53,62]$, etc. However, at present, most studies on the coupling coordination between logistics industry and economy take a single province or city as the research unit and few studies in Central Plains urban agglomeration, so the study of this paper is meaningful.

To deeply explore the level of coupling and coordination between the two systems, this paper draws on the coupling model in physics to reveal the intrinsic connection between the logistics industry and the economy. Some scholars use equation to calculate the coupling degree $[60,63,64]$.

$$
C=\sqrt{\frac{f(x) \cdot g(y)}{[f(x)+g(y)]^{2}},}
$$

where $C$ is the coupling degree of logistics industry and economic systems. The value range of $C$ is $[0,1]$. The closer the $C$ value is to 1 , the closer the cooperation between the logistics industry and the economic system is, the stronger the interaction is at the same time; conversely, the closer the value of $C$ to 0 , the weaker the degree of interconnection between the two systems is.

There are two cases of high coupling in the actual research: one is the high development level of both systems of 
TABLE 1: Grading criteria for coupling coordination.

\begin{tabular}{|c|c|c|c|}
\hline Coupling coordination & Coupling coordination level & Coupling coordination & Coupling coordination level \\
\hline $0 \leq D \leq 0.1$ & Extreme disorder & $0.5<D \leq 0.6$ & Barely coordinated \\
\hline $0.1<D \leq 0.2$ & Severe disorders & $0.6<D \leq 0.7$ & Primary coordination \\
\hline $0.2<D \leq 0.3$ & Moderate disorder & $0.7<D \leq 0.8$ & Intermediate coordination \\
\hline $0.3<D \leq 0.4$ & Mild disorders & $0.8<D \leq 0.9$ & Good coordination \\
\hline $0.4<D \leq 0.5$ & On the verge of disorder & $0.9<D \leq 1$ & Quality coordination \\
\hline
\end{tabular}

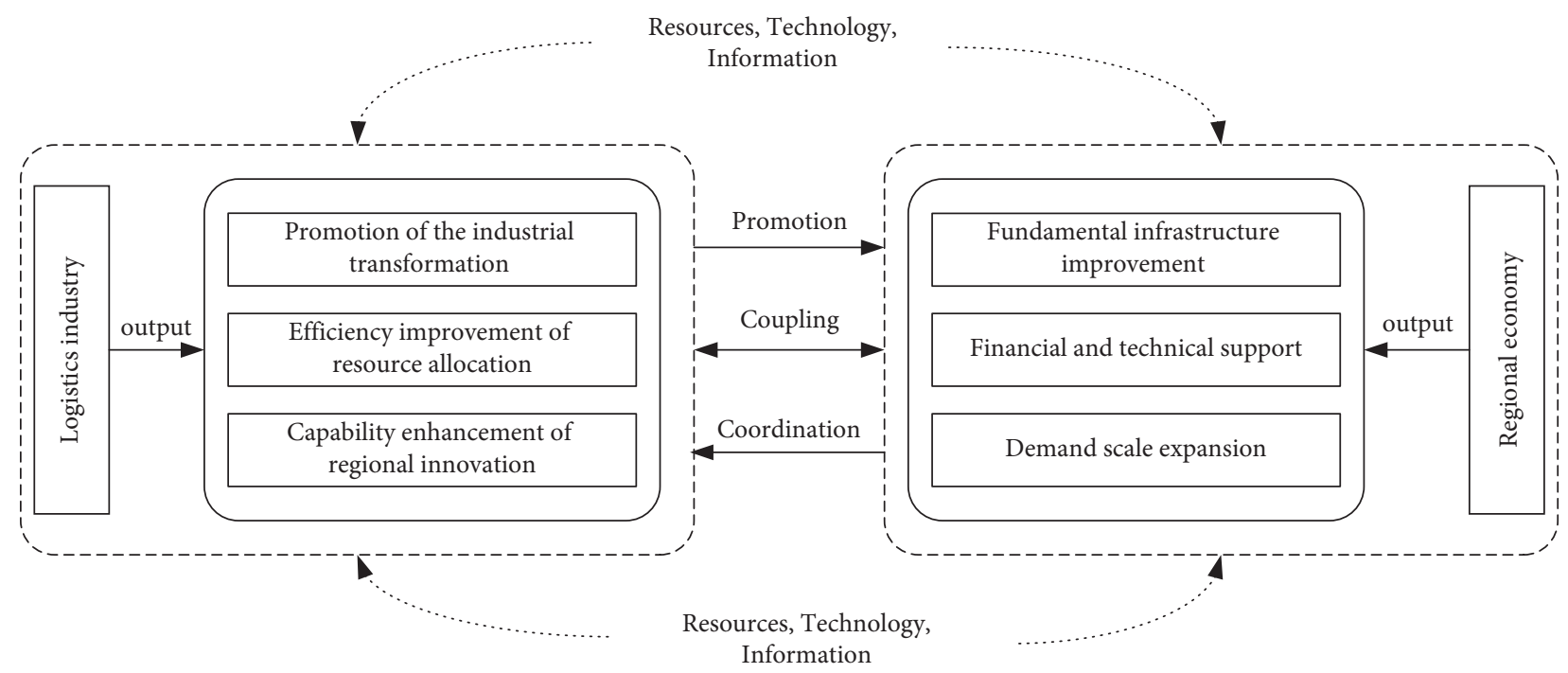

FIgURE 1: Logistics industry and economic coupling and coordination mechanism.

logistics industry and economy, and the other is the development level of both systems is low. In order to avoid the latter misleading to the actual analysis, this paper constructs a coupled coordination model to reflect the coordination status between logistics industry and economy and their respective comprehensive development levels at the same time, and the specific formula is as follows $[64,65]$.

$$
\begin{aligned}
& T=a f(x)+b g(y), \\
& D=\sqrt{C \times T},
\end{aligned}
$$

where $T$ is the comprehensive development index of logistics industry and economic system, which can reflect the overall development effect of the two systems, and $a$ and $b$, respectively, indicates the weight value of logistics industry and economy in the composite system. In this study, the two subsystems of logistics and economy are equally important, and referring to the existing research, it is taken as $a=b=$ 0.5 [66]; $D$ is the coupling coordination degree of logistics industry and economy, and the value of $D$ is taken in the range of $[0,1]$. Referring to the classification criteria of the existing literature $[21,61,67]$ and combining with the actual research results of this paper, the coupling coordination relationship $(D)$ is divided into ten levels (Table 1 ).

\subsubsection{Exploratory Spatial Data Bureau Analysis.} Exploratory spatial data analysis (ESDA) is supported by spatial analysis, emphasizes the spatial correlation of events, focuses on the nature of spatial data, and explores the spatial patterns of data [35]. In this paper, the global Moran's I index and Getis-Ord $G_{i}^{*}$ indexes are used to analyze the global and local spatial autocorrelation of the development level of logistics industry, economic development level, and the coupling coordination degree of the two in the Central Plains urban cluster, respectively.

The global Moran's I index is able to reflect the similarity of attributes of adjacent or close spatial units, which aims at revealing the spatial correlation and spatial dependence of the study area as a whole, as is found in the following equation $[68,69]$.

$$
I=\frac{N}{\sum_{i j} w_{i j}} \frac{\sum_{i} \sum_{j} w_{i j}\left(x_{i}-\bar{x}\right)\left(x_{j}-\bar{x}\right)}{\sum_{i}\left(x_{i}-\bar{x}\right)^{2}},
$$

where $N$ is the number of study area units, $x_{i}$ and $x_{j}$ denote the attribute values of study units $i$ and study units $j$, respectively, $\bar{x}$ denotes the average attribute values of all study units, and $w_{i j}$ is the spatial weight matrix. The global Moran's I index takes a range of values $[-1,1] . I<0$ indicates a negative spatial correlation, which means there is variability between adjacent regions. $I>0$ indicates a positive spatial correlation. That is to say, the research units with high (low) attribute values show agglomeration in space. $I=0$ indicates no spatial correlation.

The global spatial autocorrelation describes the average degree of agglomeration across the study space [48], but it does not delicately portray the spatial location of 
agglomerations. In this paper, we use the Getis-Ord $G_{i}^{*}$ index to detect whether high-value spatial clustering (hot spots) or low-value spatial clustering (cold spots) occurs in the local space, with the following equation [70].

$$
G_{i}^{*}=\frac{\sum_{j=1}^{n} w_{i j} x_{j}}{\sum_{j=1}^{n} x_{j}},
$$

where $n$ is the number of study units, $w_{i j}$ is the spatial weight matrix, and $x_{j}$ is the observed value of spatial units $j$. If $G_{i}^{*}$ is significant and positive, it is a hot spot area; if $G_{i}^{*}$ is significant and negative, it is a cold spot area.

3.1.4. GWR Model Construction. The traditional linear regression model is a global estimation of all samples and parameters without considering the spatial attributes of the data, while the geographically weighted regression model is solved by using locally weighted least squares, which is essentially a local regression and can well explore the spatial nonsmoothness of the parameters. The geographic weighted regression (GWR) model is a local variable coefficient model which can recognize the spatial nonstationary [40]. With the GWR model, it is possible to analyze the spatial variability of estimated coefficients of each explanatory variable [41].

$$
y_{i}=\beta_{0}\left(u_{i}, v_{i}\right)+\sum_{k} \beta_{k}\left(u_{i}, v_{i}\right) x_{i k}+\varepsilon_{i},
$$

where $y_{i}$ is the dependent variable, $x_{i k}$ is the independent variable, and $k$ indicates the number of independent variables. $\beta_{o}$ is the intercept term, and $\left(u_{i}, v_{i}\right)$ is the geographic location of the sample $i$ unit. $\beta_{k}\left(u_{i}, v_{i}\right)$ is the local regression coefficient at the $i$ point, and $\varepsilon_{i}$ is the spatial random error term.

3.2. Study Area and Data Sources. This paper selects the scope of Central Plains urban agglomeration as the research area in the development plan of Central Plains urban agglomeration approved by the State Council in 2018 (Figure 2). In total, it covers 30 cities, which are 18 provincial cities in Henan Province, as well as Heze and Liaocheng in Shandong Province, Yuncheng, Jincheng, and Changzhi in Shanxi Province, Fuyang, Bozhou, Bengbu, Huaibei, and Suzhou in Anhui Province, and Handan and Xingtai in Hebei Province, with a total area of $287,000 \mathrm{~km}^{2}$.

The development of the logistics industry can be evaluated from multiple dimensions $[60,64]$. Considering the lack of statistics specifically on logistics industry, the statistical values of transportation, storage, and postal industry which are the indicators related to logistics industry are selected to represent the statistical values of logistics industry in this study. The data used are obtained from the 2020 China Urban Statistical Yearbook, the 2020 China Regional Economic Statistical Yearbook, as well as the 2020 Statistical Yearbook and the 2019 National Economic and Social Development Statistical Bulletin of each province and city in the Central Plains urban agglomeration, and individual missing data are obtained based on the average annual growth rate.

\section{Coupling Coordination Analysis}

4.1. Constructing the Index System. According to the connotation of coupled and coordinated development of logistics industry and economy and the research results of existing scholars $[20,21]$, the construction principles have been addressed from the perspective of scientific, comprehensive, representative, and operable dimensions. Besides, the respective development characteristics of logistics industry and economy have been taken into account, as well as the internal linkage development relationship between the two systems. Based on the above considerations, the comprehensive evaluation index system of logistics industry and economy is constructed, illustrated in Table 2. The ten indicators to measure the comprehensive level of the logistics industry are selected from industrial scale, industrial foundation, and development potential viewpoint. Ten indicators were collected from four aspects of economic efficiency, economic structure, opening-up, and people's livelihood to measure the comprehensive level of the economy.

4.2. Evaluation of the Comprehensive Development Level. According to the comprehensive evaluation index system of logistics industry and economy, and using formula (1), the comprehensive level values of the two systems of each prefecture-level city in the Central Plains City Cluster in 2019 were calculated (Table 3 ).

(1) The comprehensive development level of logistics industry. From Table 3, the average value of the comprehensive development index of the logistics industry in the Central Plains City Cluster is 0.1696, and only $27.67 \%$ of the cities are above the average value, so it can be seen that the overall development level of the logistics industry in the Central Plains City Cluster is low. The standard deviation of the integrated development index of the logistics industry in the Central Plains City Cluster is 0.0890 , in which the development level of the logistics industry in Heze is the highest, with the integrated development index of 0.4623 . However, the development level of the logistics industry in Kaifeng is the lowest, with the integrated development index of 0.0894. It can be seen from the above data that the development level of the logistics industry in each prefecture-level city in the Central Plains City Cluster has a large gap, in which the integrated development level of the logistics industry in Heze is much higher than other cities. The overall development level of logistics industry in the Central Plains City Cluster is "one of the best."

(2) Comprehensive economic development level. As calculated from Table 3, the average value of the Central Plains City Cluster Economic Comprehensive Development Index is 0.2246 , and only $36.67 \%$ of the cities are above the average value, indicating that the overall economic development level of the 


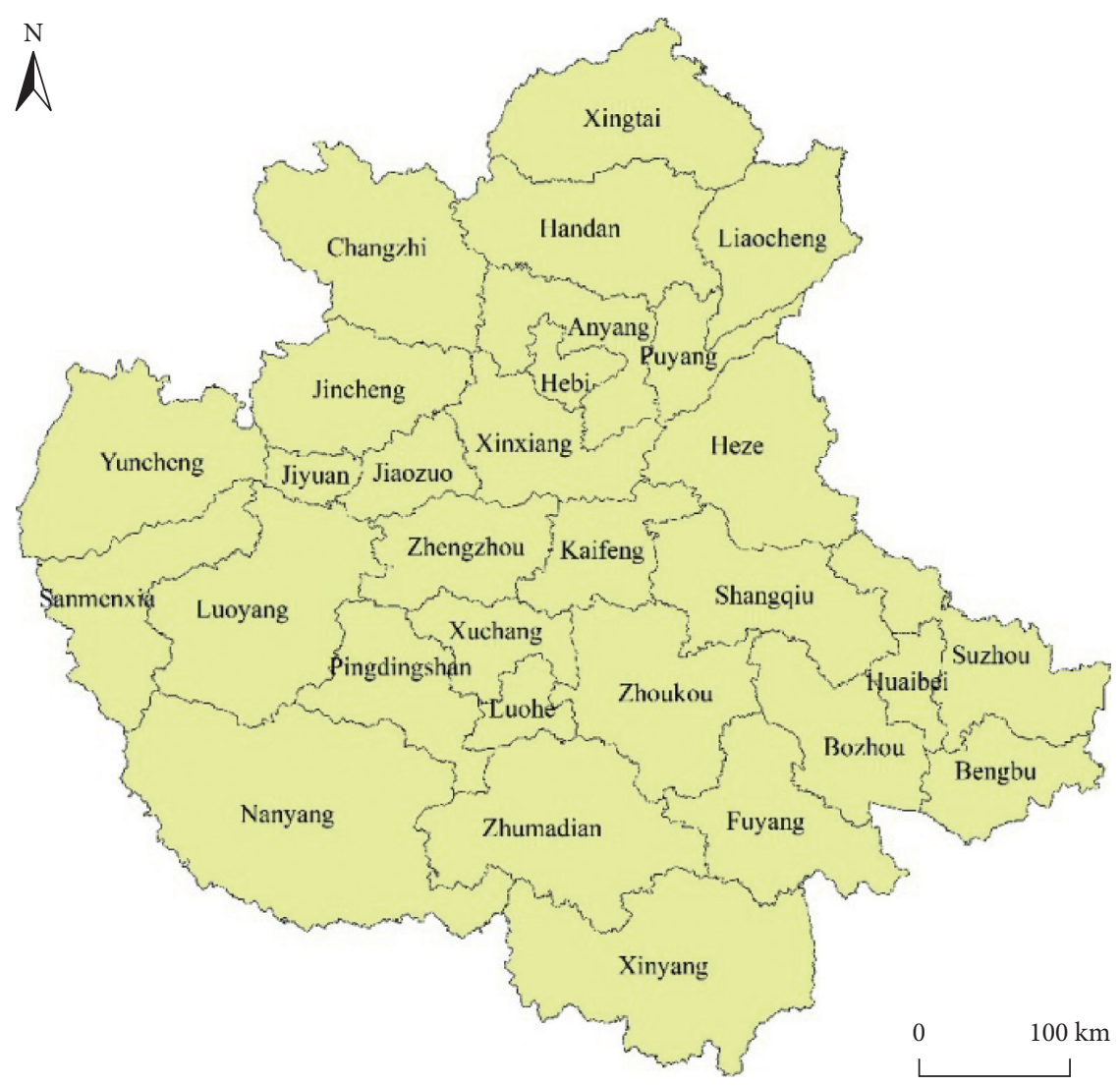

Figure 2: Central Plains City Cluster location map.

TABLE 2: Logistics industry and economic development comprehensive evaluation index system.

\begin{tabular}{|c|c|c|c|c|}
\hline System & Tier 1 indicators & Secondary indicators & Unit & Weights \\
\hline \multirow{10}{*}{$\begin{array}{l}\text { Logistics industry } \\
\text { system }\end{array}$} & \multirow{4}{*}{ Industry scale } & Freight volume per capita & $\mathrm{t} /$ person & 0.0627 \\
\hline & & Cargo turnover per capita & $\mathrm{t}-\mathrm{km} /$ person & 0.0652 \\
\hline & & $\begin{array}{l}\text { Total postal and telecommunications services per } \\
\text { capita }\end{array}$ & Yuan/person & 0.1003 \\
\hline & & $\begin{array}{c}\text { Value added of transportation, storage, and postal } \\
\text { industry per capita }\end{array}$ & Yuan/person & 0.0917 \\
\hline & \multirow{4}{*}{ Industrial base } & Civilian car ownership per capita & Vehicle/person & 0.0957 \\
\hline & & $\begin{array}{c}\text { Number of cell phone subscribers at the end of the } \\
\text { year }\end{array}$ & 10,000 households & 0.0635 \\
\hline & & Number of Internet users & 10,000 households & 0.0980 \\
\hline & & Road density & $\begin{array}{l}\text { Kilometers per } 100 \text { square } \\
\text { kilometers }\end{array}$ & 0.1629 \\
\hline & \multirow{3}{*}{$\begin{array}{l}\text { Development } \\
\text { potential }\end{array}$} & $\begin{array}{c}\text { Transportation, storage, postal industry urban units } \\
\text { employed }\end{array}$ & 10,000 people & 0.0944 \\
\hline & & Number of express delivery per 10,000 people & Pieces/person & 0.1655 \\
\hline \multirow{10}{*}{ Economic system } & & GDP per capita & Yuan/person & 0.0761 \\
\hline & \multirow{3}{*}{ Economic benefits } & Fiscal revenue per capita & Yuan/person & 0.1191 \\
\hline & & Total retail sales of social consumer goods per capita & Yuan/person & 0.0772 \\
\hline & & Total social fixed asset investment per capita & Yuan/person & 0.0968 \\
\hline & \multirow{2}{*}{ Economic structure } & Share of secondary industry in GDP & $\%$ & 0.0697 \\
\hline & & Share of tertiary sector in GDP & $\%$ & 0.0495 \\
\hline & \multirow{2}{*}{ Open to the public } & Actual use of foreign capital per capita & USD/person & 0.1034 \\
\hline & & Total import and export per capita & USD/person & 0.2650 \\
\hline & \multirow{2}{*}{ People's life } & Per capita disposable income of urban residents & Yuan/person & 0.0598 \\
\hline & & Per capita disposable income of rural residents & Yuan/person & 0.0834 \\
\hline
\end{tabular}


TABLE 3: Level of comprehensive development and coupling coordination between logistics industry and economy in Central Plains City Cluster.

\begin{tabular}{|c|c|c|c|c|c|c|}
\hline City & $f(x)$ & $g(y)$ & $C$ & $T$ & $D$ & Evaluation \\
\hline Zhengzhou & 0.4547 & 0.7345 & 0.9719 & 0.5946 & 0.7602 & Intermediate coordination and lagging development of logistics industry \\
\hline Kaifeng & 0.0894 & 0.1696 & 0.9509 & 0.1295 & 0.3510 & Mildly dysfunctional, logistics industry lags behind \\
\hline Luoyang & 0.1629 & 0.3007 & 0.9548 & 0.2318 & 0.4704 & e verge of coordination, the development of logistics industry lags behind \\
\hline Pingdingshan & 0.0994 & 0.1603 & 0.9721 & 0.1298 & 0.3553 & Mildly dysfunctional, logistics industry lags behind \\
\hline Anyang & 0.3024 & 0.1737 & 0.9628 & 0.2381 & 0.4787 & On the brink of dislocation and lagging economic development \\
\hline Hebi & 0.1094 & 0.3025 & 0.8834 & 0.2060 & 0.4265 & On the verge of dislocation, the logistics industry is lagging behind \\
\hline Xinxiang & 0.2080 & 0.2010 & 0.9999 & 0.2045 & 0.4522 & On the brink of dislocation and lagging economic development \\
\hline Jiaozuo & 0.1753 & 0.2937 & 0.9676 & 0.2345 & 0.4763 & On the verge of coordination, the logistics industry is lagging behind \\
\hline Puyang & 0.1257 & 0.1699 & 0.9887 & 0.1478 & 0.3823 & Mildly coordinated, lagging logistics industry \\
\hline Xuchang & 0.1212 & 0.2614 & 0.9304 & 0.1913 & 0.4219 & erge of dislocation, the logistics industry is laggin \\
\hline Luohe & 0.1329 & 0.2498 & 0.9522 & 0.1913 & 0.4268 & On the verge of dislocation, the logistics industry is lagging $\mathrm{b}$ \\
\hline Sanmenxia & 0.1176 & 0.3140 & 0.8904 & 0.2158 & 0.4383 & On the verge of coordination, the \\
\hline Nanyang & 0.1396 & 0.1362 & 0.9999 & 0.1379 & 0.3713 & nomic development \\
\hline Shangqiu & 0.1677 & 0.1199 & 0.9861 & 0.1438 & 0.3766 & Mild dislocation and lagging economic development \\
\hline Xinyang & 0.0999 & 0.1103 & 0.9988 & 0.1051 & 0.3240 & Mildly dysfunctional, logistics industry lags behind \\
\hline Zhoukou & 0.1109 & 0.0936 & 0.9964 & 0.1022 & 0.31 & Mild dislocation and lage \\
\hline Zhumadian & 0.0956 & 0.1079 & 0.9982 & 0.1017 & 0.3186 & stics industry lags behind \\
\hline Jiyuan & 0.1285 & 0.6943 & 0.7259 & 0.4114 & 0.5465 & gistics industry lags behind \\
\hline Changji & 0.1805 & 0.1933 & 0.9994 & 0.1869 & 0.4322 & he verge of dislocation, the logistics industry is lagging $b$ \\
\hline Jincheng & 0.1361 & 0.2302 & 0.9665 & 0.1832 & 0.4208 & On the verge of dislocation, the log \\
\hline heng & 0.1249 & 0.0724 & 0.9641 & 0.0987 & 0.3 & Mild dislocation and lagging economic development \\
\hline Xingtai & 0.1517 & 0.1340 & 0.9981 & 0.1429 & 0.3776 & Mild dislocation and lagging economic development \\
\hline Handan & 0.1642 & 0.1893 & 0.9975 & 0.1768 & 0.4199 & On the verge of dislocation, the logistics industry is lagging \\
\hline Liaocheng & 0.2402 & 0.1611 & 0.9804 & 0.2007 & 0.4435 & On the brink of dislocation and lagging econ \\
\hline Heze & 0.4623 & 0.1667 & 0.8827 & 0.3145 & 0.5268 & onomic development lags \\
\hline Huaibei & 0.1426 & 0.1681 & 0.9966 & 0.1553 & 0.3935 & Mildly dysfunctional, logistics industry lags behind \\
\hline Bozhou & 0.1528 & 0.1596 & 0.9998 & 0.1562 & 0.3952 & Mildly dysfunctional, logistics industry lags behind \\
\hline Cebu & 0.1342 & 0.1950 & 0.9828 & 0.1646 & 0.4022 & On the verge of dislocation, the logistics industry is lagging behind \\
\hline Bengbu & 0.1968 & 0.2376 & 0.9956 & 0.2172 & 0.4651 & On the verge of coordination, the logistics industry is lagging behind \\
\hline Fuyang & 0.1610 & 0.2372 & 0.9815 & 0.1991 & 0.4421 & On the verge of dislocation, the logistics industry is lagging behind \\
\hline
\end{tabular}

Central Plains City Cluster needs to be improved. The standard deviation of economic comprehensive development index of Central Plains City Group is 0.1452 , among which the highest level of development is 0.7345 in Zhengzhou City and the lowest level of development is 0.0715 , which shows that the economic development of each prefecture-level city in Central Plains City Group is unbalanced. The central city Zhengzhou has much higher comprehensive economic development level than other cities in the Central Plains urban agglomeration and has become the "leader" of the economic development of the Central Plains City Cluster.

4.3. Spatial Pattern Analysis of the Coupling Coordination Degree. In order to further analyze the interaction mechanism between logistics industry and economy, on the basis of the coupling coordination model to analyze the coupling coordination relationship between the two systems, the relative development degree is used to reveal the relative development status. If $f(x)<g(y)$, the development of logistics industry lags behind the economy; if $f(x)=g(y)$, the logistics industry and economy develop simultaneously; if $f(x)>g(y)$, the economy development lags behind the logistics industry. The coupling coordination values of 30 prefecture-level cities are calculated according to equations (2)-(4) (Table 3), and the spatial distribution of coupling coordination degree of each city is drawn using ArcGIS, illustrated in Figure 3.

From an overall perspective, the mean value of coupling coordination between logistics industry and economy in the Central Plains City Cluster is 0.9625 , and the overall level of coordinated development is high and in a high-quality coordinated state. It indicates that the logistics industry and the economy of the Central Plains City Cluster are closely coordinated within the two systems. The standard deviation of coupling coordination degree is 0.0553 , which indicates that the difference of coupling coordination level between cities is small. Combined with Table 3 , the coupling coordination values of 30 prefecture-level cities range from 0.7259 to 0.9999 . The coupling coordination relationship covers three types of primary coordination, intermediate coordination, and high-quality coordination. This shows that the "difference" of coupling coordination degree is obvious. From the perspective of individual cities, Nanyang City has the highest degree of coordination and Jiyuan City has the lowest degree of coordination. This is because the economic development of Jiyuan City lags behind the logistics industry, it plays a weak supporting role for the logistics industry, and the internal integration of the two systems is difficult and in a state of mild dysfunction. 


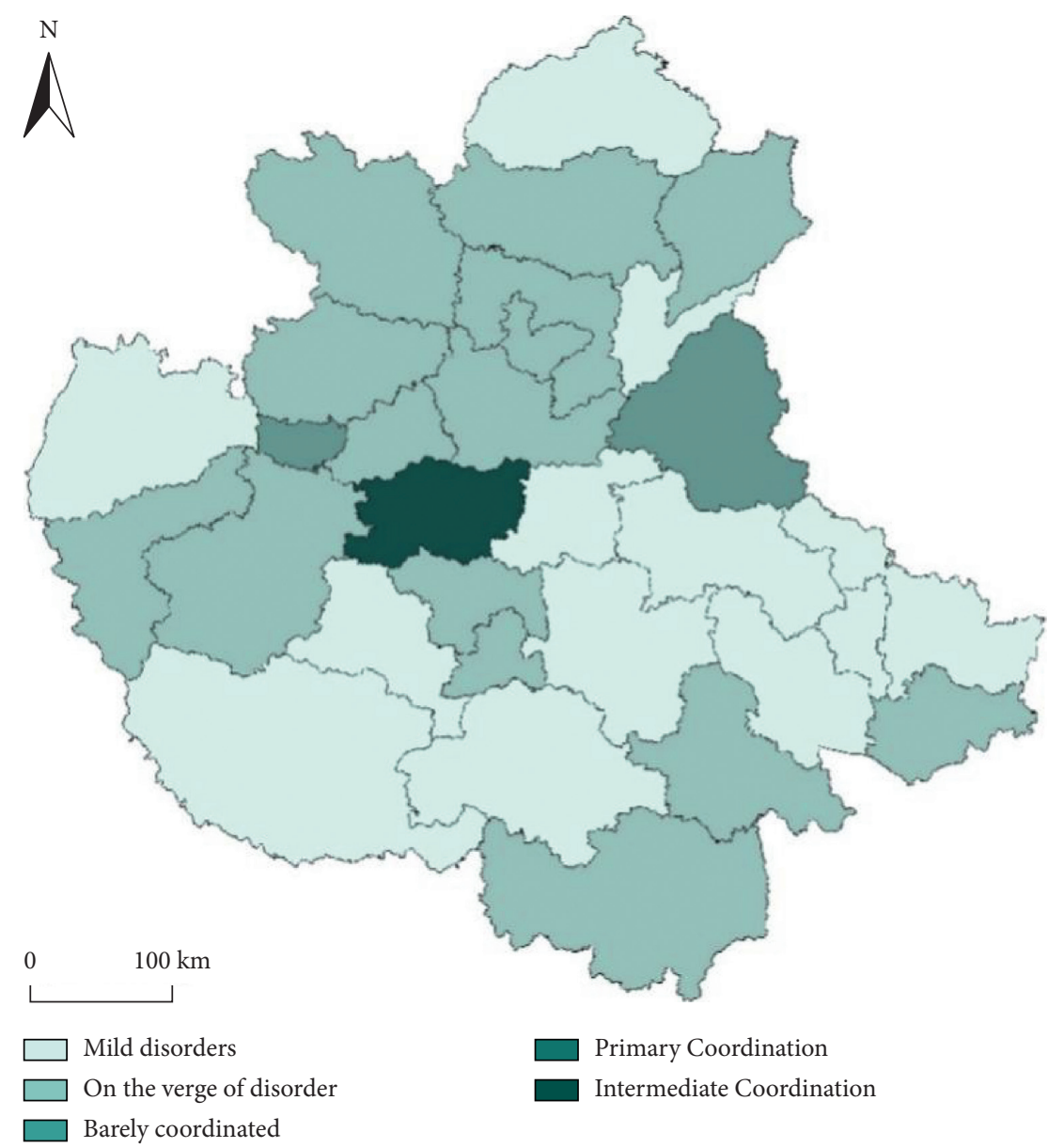

FIgUre 3: Spatial pattern of logistics industry and economic coupling coordination in the Central Plains City Cluster.

From the viewpoint of spatial distribution in Figure 3, the overall coordination between logistics industry and economy in the Central Plains City Cluster is "high in the center and low around." Among them, only the central city Zhengzhou is at the stage of high-quality coordination; 15 prefecture-level cities are on the verge of dysfunctional regulation, accounting for $50 \%$ of the total, which are the main coordination type of the Central Plains City Cluster. They mainly distributed in the north and southwest; 12 prefecture-level cities are at the stage of mild dysfunction, mainly distributed in the eastern and southern regions. Zhengzhou and Luoyang, as the central and subcentral cities of the Central Plains City Cluster, respectively, provide strong guarantee for the development of logistics industry. The circulation of economy and logistics industry is good in these two cities; the development speed of logistics industry is lower than that of economy in north and southwest of the Central Plains City Cluster. The economic development of these five cities, Shangqiu, Zhoukou, Nanyang, Yuncheng, and Xingtai, is behind of development of the logistics industry. However, the seven regions (Kaifeng, Pingdingshan, Xinyang, Puyang, Zhumadian, Huaibei, and Bozhou) have an opposite situation where logistics industry is behind of the development of its economy, resulting in a mild dislocation stage.

\subsection{Spatial Autocorrelation Analysis}

4.4.1. Global Spatial Autocorrelation Analysis. According to equation (5), the development level of logistics industry, economic development level, and the global Moran's I index of coupling coordination degree of the two were measured separately using ArcGIS software in the Central Plains urban agglomeration (Table 4). The Moran's I index of the comprehensive development index of logistics industry is 0.1008 , and the $Z$ value of the significance test is 1.7128 , which is greater than the critical value of 1.65 at $10 \%$ significance level, indicating that the logistics industry in the study area is not independent in space, showing certain spatial clustering characteristics. The Moran's I index of comprehensive economic development index is 0.1697 , and the $Z$ value of significance test is 2.1602 , which is greater than the critical value of 1.96 at $5 \%$ significance 
TABLe 4: Global Moran's I index statistics.

\begin{tabular}{lccc}
\hline Evaluation object & Moran's $I$ & $P$ value & $Z$ score \\
\hline $\mathrm{f}(\mathrm{x})$ & 0.1008 & 0.0868 & 1.7128 \\
$\mathrm{~g}(\mathrm{y})$ & 0.1697 & 0.0308 & 2.1602 \\
$\mathrm{D}$ & 0.2361 & 0.0050 & 2.8052 \\
\hline
\end{tabular}

level, indicating that the economy of each city is not randomly distributed spatially, but showing a significant positive spatial agglomeration characteristic. The Moran's I index of coupling coordination degree is 0.2361 , and the $Z$ value of significance test is 2.8052 , which is greater than the critical value of 2.58 at $1 \%$ significance level, indicating that the spatial correlation of coupling coordination degree of each municipality is strong and the clustering effect is obvious. The municipalities with low coupling coordination degree are agglomerated, which is consistent with their spatial distribution.

4.4.2. Local Spatial Autocorrelation Analysis. The global Moran's I index analyzes the correlation between the logistics industry, economy, and the coupling and coordination of the two in each prefecture-level city as a whole, but it cannot identify the heterogeneity of spatial autocorrelation among different study units. Therefore, in order to further explore the spatial heterogeneity of the logistics industry, economy, and the coupling and coordination of the two in each study unit in detail, this paper adopts the Getis-Ord $G_{i}^{*}$ index to analyze the local spatial autocorrelation. According to equation (6), the Getis-Ord index is divided into four types: hot spot, subhot spot, cold spot, and subcold spot; by using ArcGIS natural intermittent point method and the cold and hot spots, pattern segment is generated as shown in Figure 4. From Figure 4, we can get the local spatial autocorrelation analysis of the development level of logistics industry, economic development level, and the coupling coordination degree of logistics industry and economy in each city.

(1) The development level of logistics industry in the Central Plains urban agglomeration is characterized by few hot spots and many cold spots, showing a spatial distribution of "hot in the Middle East and cold in the north and south." Among them, the hot spot areas are distributed in the Middle East with Zhengzhou as the core and show spreading tendency to the neighboring regions. The direction of spreading is mainly to the middle and east, and the cold spot areas are mainly concentrated in the south, showing the spreading trend to the east.

(2) The economic development level of the Central Plains urban agglomeration is characterized by the predominance of cold spots and subcold spots, and fewer hot spots and subhot spots, showing a spatial pattern of "hot in the Middle East and cold in the southeast." The hot spots are distributed in the central and western regions, including nine prefecture-level cities, Zhengzhou, Luoyang, Xinxiang,
Jiaozuo, Xuchang, Pingdingshan, Jiyuan, Yuncheng, and Jincheng; the secondary hot spots are scattered in the periphery of the hot spots, including Kaifeng, Changzhi, Hebi, Anyang, Sanmenxia, and Nanyang; the secondary cold spots are mostly distributed in the northeastern part of the city group, and a few are distributed in the southwestern and southeastern parts, covering Xinyang and Puyang. The cold spots are mainly concentrated in Shangqiu, Zhoukou, Zhumadian, Fuyang, Heze, and the southern municipalities, which are the southern cities with obvious clustering characteristics.

(3) The spatial differentiation of the hot and cold spots of the coupling and coordination degree of the two systems in the Central Plains urban agglomeration is significant, with the hot spots distributed in Zhengzhou, Luoyang, Jiaozuo, and Xinxiang, indicating that the cities with high coupling and coordination are distributed in high-density and smallscale clusters. The secondary hot spots are distributed in a ring around the hot spots, which shows that Zheng-Luo-Jiao-Xin cities have a radiation-driven influence on the coordinated development of logistics industry and economy in their surrounding cities to a large extent. The subcold spots occupy the most municipal areas and are distributed in the northeast area in a row, contiguously distributed in the northeast and a few in the southwest area; the cold spots are distributed in the southern area in a group.

\section{Influencing Factor Analysis of the Coupling Coordination}

5.1. Variable Design. The logistics industry is a basic industry of the national economy, and it promotes the regional economic development through synergistic development with related industries, while the healthy development of the regional economy also provides a stable macroenvironment for the development of the logistics industry and expands the demand for the logistics industry, but the coupling and coordination between the two are also influenced by many factors. Based on the previous publications [71-73], four independent variables are selected to explore the factors influencing the spatial distribution of the coupled coordination development level of logistics industry and economy in the Central Plains urban agglomeration (Table 5), including urbanization rate, educational development level, science and technology level, and population density.

In order to prevent the collinearity of the indicators from causing deviation to the research results, we use SPSS 


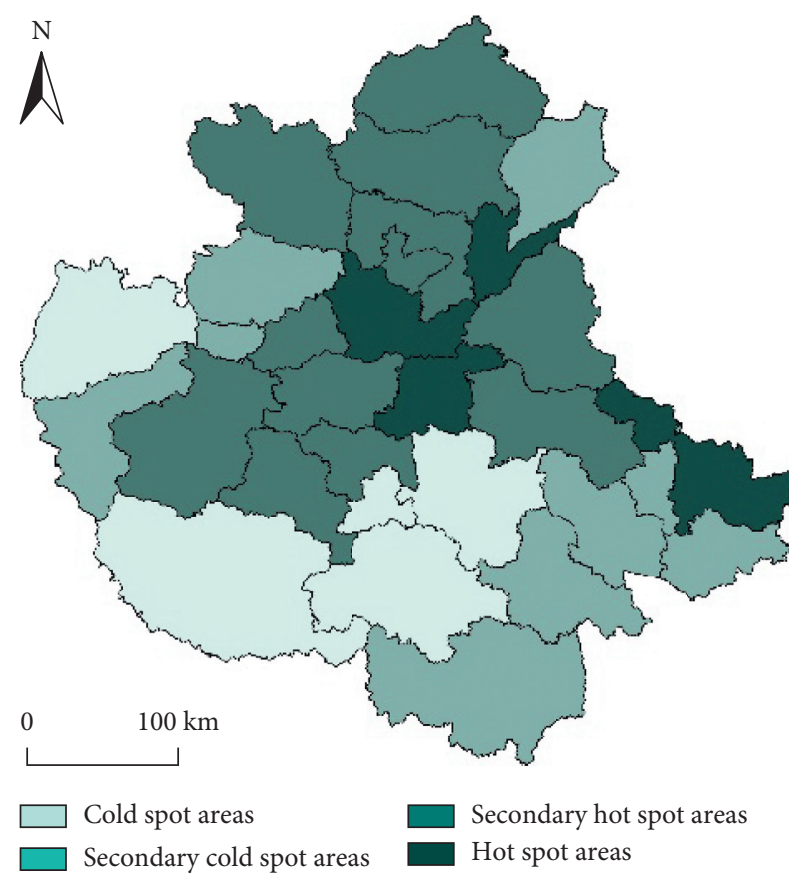

(a)

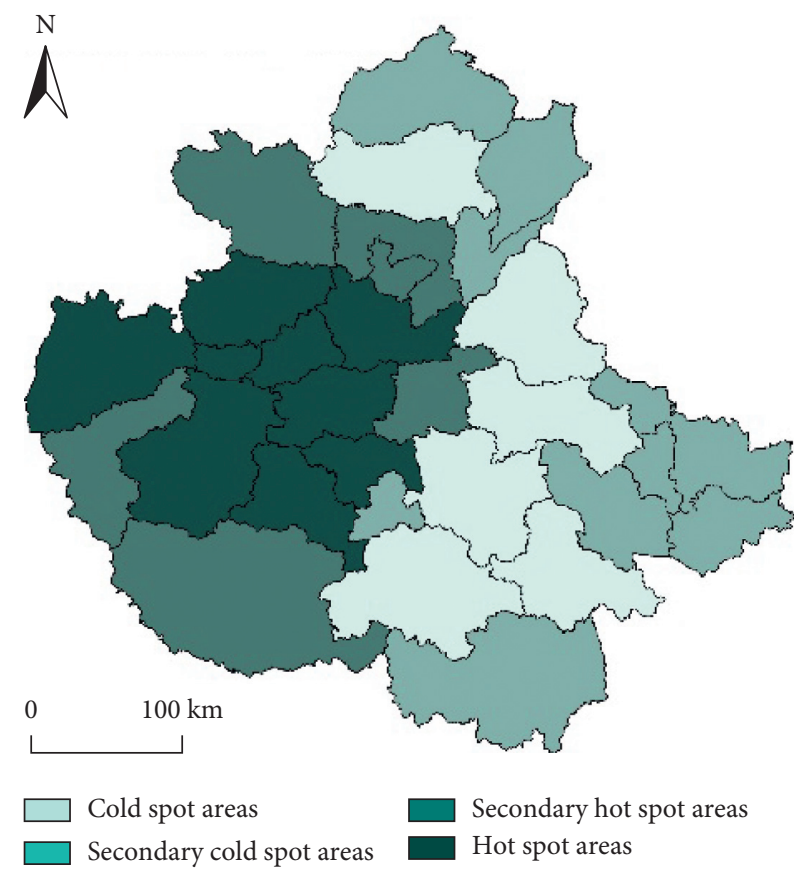

(b)

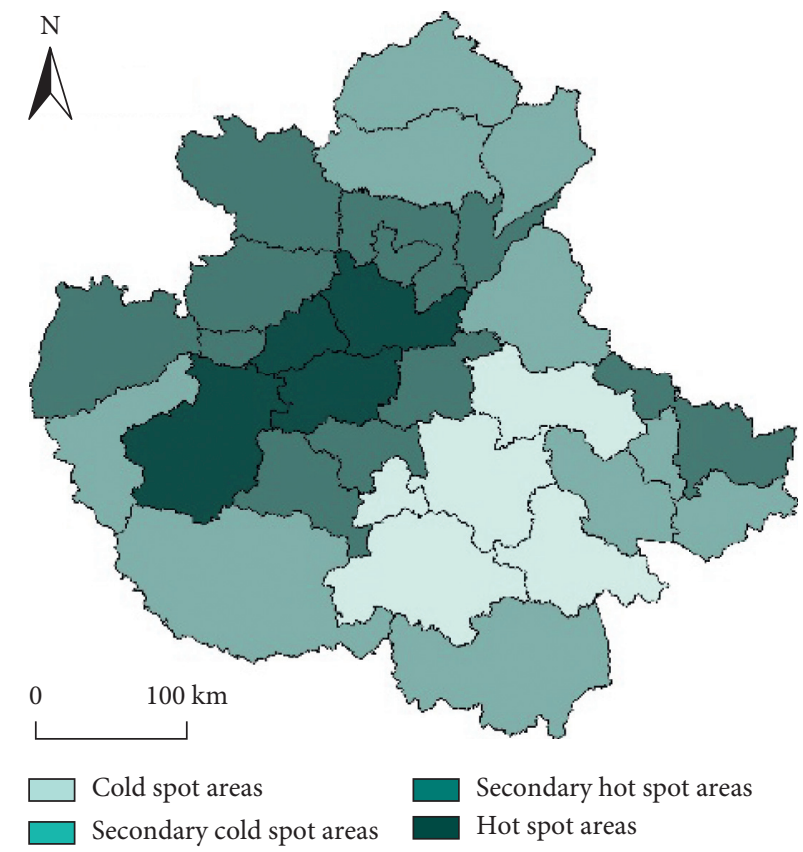

(c)

FIGURE 4: Spatial pattern of logistics industry, economic development level, and cold and hot spots of coupling and coordination of the two systems in the Central Plains City Cluster.

TABLE 5: Influencing factor index system.

\begin{tabular}{lcc}
\hline Influencing factors & Explanation of indicators & Unit \\
\hline Urbanization rate & Urban population share & $\%$ \\
Education development level & Number of students enrolled in general higher education institutions & People \\
Technology level & R\&D internal expenses & Million yuan \\
Population density & Total city population/total city area & People/km2 \\
\hline
\end{tabular}


TABLE 6: Results of multicollinearity test.

\begin{tabular}{|c|c|c|c|c|c|c|c|}
\hline \multirow{2}{*}{ Models } & \multicolumn{2}{|c|}{$\begin{array}{c}\text { Nonstandardized } \\
\text { coefficient }\end{array}$} & \multirow{2}{*}{$\begin{array}{l}\text { Standard } \\
\text { coefficient }\end{array}$} & \multirow{2}{*}{$t$} & \multirow{2}{*}{ Sig. } & \multicolumn{2}{|c|}{$\begin{array}{l}\text { Covariance } \\
\text { statistics }\end{array}$} \\
\hline & $B$ & $\begin{array}{l}\text { Standard } \\
\text { error }\end{array}$ & & & & Tolerances & VIF \\
\hline \multirow{5}{*}{$\begin{array}{l}\text { 1. Urbanization rate } 2 \text {. Number of students in general higher } \\
\text { education institutions } 3 \text {. R\&D internal expenses } 4 \text {. Population } \\
\text { density }\end{array}$} & 0.362 & 0.030 & & 11.922 & 0.000 & & \\
\hline & 0.227 & 0.064 & 0.419 & 3.541 & 0.002 & 0.704 & 1.420 \\
\hline & 0.152 & 0.138 & 0.213 & 1.102 & 0.281 & 0.264 & 3.791 \\
\hline & 0.237 & 0.121 & 0.377 & 1.953 & 0.062 & 0.264 & 3.787 \\
\hline & 0.137 & 0.062 & 0.226 & -2.203 & 0.037 & 0.940 & 1.063 \\
\hline
\end{tabular}

software to test the collinearity of the independent variables in the regression analysis, calculate the correlation coefficient between the independent variables, and select the variance expansion factors as the evaluation index to test, found in Table 6 [74]. It can be seen that the VIF values of all four variables are within 4 , and the mean VIF value is 2.515 . According to the diagnosis of multicollinearity, if there is multicollinearity between variables when the mean VIF value $>1$ and VIF $>10$, the estimation error will increase [75]; therefore, there is no multicollinearity problem between the independent variables.

The improvement of urbanization level can drive logistics demand. On the one hand, the acceleration of urbanization has greatly improved logistics infrastructure. The standardization of equipment and automation level of ascension provides the foundation platform for the smooth running of the modern logistics industry and enhances the efficiency of logistics operation. On the other hand, urbanization makes the population convergence and change the lifestyle. Residents have more sophisticated logistics service demand, which makes the logistics enterprise needs to provide higher quality service in urban distribution, trade logistics, cold chain logistics, and other fields. The development of urbanization has not only driven the rapid improvement of rural land economy and urban industrial service, but created a large number of employment opportunities. The transfer of rural population to cities as labor force drives the development of the second and third industries on both sides, which is conducive to promoting the development of regional economy. In addition, the improvement of the level of urbanization has improved the problem of overcapacity in the secondary industry of enterprises, fundamentally improving the economic benefits of the industry, but also driving the development of the national economy. Moreover, by optimizing the combination of input factors in the process of urbanization, the same or less input factors can be promoted to achieve higher economic benefits. Moreover, the improvement of urbanization level can stimulate the consumption potential of rural population, promote the continuous expansion of market scope, and also bring more consumer demand, thus promoting economic growth.

The improvement of education level can create rich human resources for a region and provide sufficient human capital guarantee for the development of logistics industry. More high-quality logistics practitioners contribute to regional logistics information and integration development. In addition, a region of high education level also means the area of high production, alignment, accordingly, the future development of logistics industry in the region space. The level of economic development of a region largely depends on the educational development. Education can improve the quality of human capital and promote the ascent of the total factor productivity; education can improve people's knowledge and skills, contribute more needed for industrial workers, and promote upgrading of the industrial structure; the improvement of education level can liberate more farmers from the land and enter the secondary or tertiary industry in cities and towns; education can adjust income distribution structure and expand the middle-income groups and residents' consumption growth; education promoted to the level of science and technology innovation provides the support.

The promotion of science and technology can promote the development of logistics industry. First, the development of transportation technology saves a lot of time and costs for the logistics industry, and improves the production level and efficiency of the logistics industry, which can promote the rapid development of the logistics industry. Secondly, the development of logistics information technology has promoted the automation of logistics operations and improved the accuracy and speed of all aspects of logistics operations. At the same time, logistics information technology has strengthened the items of information acquisition, tracking, and control. This enables the logistics process to be completed more efficiently and smoothly. Logistics information technology can contribute to the production of high-level logistics value-added services and improve the regional logistics competitiveness. Third, logistics equipment technology has a role in the development of logistics industry, and logistics activity often appears in the continuous improvement of hardware and tools, saves a space for the logistics industry, and improves the efficiency. Scientific and technological progress plays an important role in improving total factor productivity and realizing connotative and intensive growth. Technological progress has changed the modes of production and transport, and the economic and trade between countries are increasingly shifting from extensive to intensive, from high consumption, high pollution, and low output to the pursuit of low energy consumption and high efficiency of green and sustainable development. For a region, first of all, the improvement of scientific and technological level can promote the sustainable and stable development of regional economy, specifically promoting the 
diversification of the region's industrial structure, promoting the development of more emerging industries, and opening up new employment channels. In addition, the improvement of scientific and technological level can promote the improvement of factor input efficiency, which is an important part of the economy to achieve intensive growth. And the rationalization of industrial structure in the area is to realize the regional economic growth. Science and technology level of industry to provide support and guidance for regional industrial structure plays an important role in the optimization and upgrade.

Population density refers to the population per unit land area. Within a certain range, the rise in population density can bring abundant human capital for the enterprise and at the same time helps concentrate on production factors and improve the utilization rate of resources and the development of logistics industry and economic growth. Population density has both positive and negative effects on economic development. When the population density is too high, it may also hinder the development of logistics industry and economic growth. When the urban population exceeds the carrying capacity of urban infrastructure, it may cause traffic congestion, shortage of public resources and other problems, and inhibit the development of logistics industry and economic growth.

\subsection{Analysis of GWR Model Regression Results}

5.2.1. GWR Model Regression Results. The GWR model was used to analyze the differences in the spatial roles of the influencing factors on the coupling coordination of the two systems, where the kernel type was set to FIXED and the model bandwidth was AICc, and the results of the operation are shown in Table 7 . The fitness of the model has reached 0.8144 , with good fitting performance.

The GWR model is a local regression analysis for each spatial unit, the values of each coefficient obtained are counted, and their maximum, upper quartile, median, lower quartile, minimum, and mean values are calculated. It can be seen that the effect of each influencing factor on the coupled and coordinated development of logistics industry and economy is spatially heterogeneous. In terms of the positive and negative regression coefficients, urbanization rate, educational development level, and science and technology level show significant positive effects, while population density shows significant negative effects. In terms of the mean values of the regression coefficients, the degree of influence of the four variables on the coupling of logistics industry and economy in the Central Plains urban agglomeration is in the following order: urbanization rate$>$ science and technology level $>$ education level $>$ population density.

5.2.2. Analysis of Influencing Factors. The regression coefficients of each influencing factor in the GWR model results are visualized and analyzed by ArcGIS software to obtain the spatial distribution map of each influencing factor. And then, we analyze the spatial heterogeneity of the driving effect of each influencing factor on the coupled and coordinated development of logistics industry and economy. The details are as follows.

(1) As shown in Figure 5, the urbanization rate has a positive effect on the coupled development of logistics industry and economy in the Central Plains urban agglomeration. The regression coefficients range from 0.1427 to 0.3235 , indicating that improving the urbanization level is an important way to promote the coupled and coordinated development of the two systems. Spatially, the spatial pattern shows a hierarchical belt pattern decreasing from northwest to southeast. The high value of regression coefficient is concentrated in Nanyang, Pingdingshan, Luoyang, Sanmenxia, Changzhi, Jincheng, Jiyuan, Jiaozuo, Zhengzhou, and Yuncheng in the northwest belt. They are rich in natural resources and are conducive to attracting foreign enterprises and are able to lay the material and institutional foundation for the logistics industry and economic development. On the other hand, they can accelerate the material circulation among neighboring cities and absorb the development dividend brought by Zhengzhou City through the diffusion effect, contributing to gathering capital, human resources, science and technology, and other production factors for the development of logistics industry and economy. The areas with low regression coefficients are mainly concentrated in the seven cities of Xinyang, Fuyang, Bozhou, Shangqiu, Suzhou, Huaibei, and Bengbu in the southeast. These seven cities are located at the junction of the provincial capitals of Henan, Shandong, and Hebei Province. Under the influence of interest barrier, the flow of resources among the seven cities is not smooth. The industrial development gap between these cities is gradually expanding, which affects the spatial layout of logistics industry. Despite the continuous development of urbanization, the improvement of regional consumption power is not obvious. The driving force of coupling and coordination between logistics industry needs to be improved.

(2) As shown in Figure 5, education level has a positive effect on the coupled development of logistics industry and economy in the Central Plains urban cluster. The regression coefficient ranges from 0.0079 to 0.3659 . Spatially, it shows a hierarchical band-like spatial pattern decreasing from southwest to northeast. The high value of the regression coefficient is concentrated in Nanyang, Pingdingshan, Zhumadian, Luohe, Xuchang, Zhengzhou, and Kaifeng in the southwest belt, which are relatively rich in talent resources and can, on the one hand, integrate with other local production factors to promote enterprise innovation and technological innovation, enhance local productivity, and boost economic growth; on the other hand, the concentration of talent will, to a certain extent, increase the demand for high-quality 
TABLE 7: Results of GWR model operations.

\begin{tabular}{|c|c|c|c|c|c|c|}
\hline Variables & Maximum value & Upper quartile & Median & Lower quartile & Minimum value & Average value \\
\hline Urbanization rate & 0.3235 & 0.2649 & 0.2208 & 0.2001 & 0.1427 & 0.2283 \\
\hline Education level & 0.3659 & 0.2535 & 0.1643 & 0.0808 & 0.0079 & 0.1775 \\
\hline Technology level & 0.3132 & 0.2833 & 0.2261 & 0.1489 & 0.0620 & 0.2107 \\
\hline Population density & -0.0842 & -0.1190 & -0.1399 & -0.1713 & -0.1971 & -0.1445 \\
\hline Residual squares $=0.0865$ & $\mathrm{AICc}=-63.3417$ & $R 2=0.8144$ & Calibration $R 2=0.7367$ & $\operatorname{Sig}=0.0651$ & & \\
\hline
\end{tabular}

$\AA$

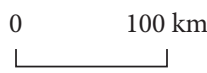

$0.0571-0.0949$ $0.0950-0.1394$

N (a)

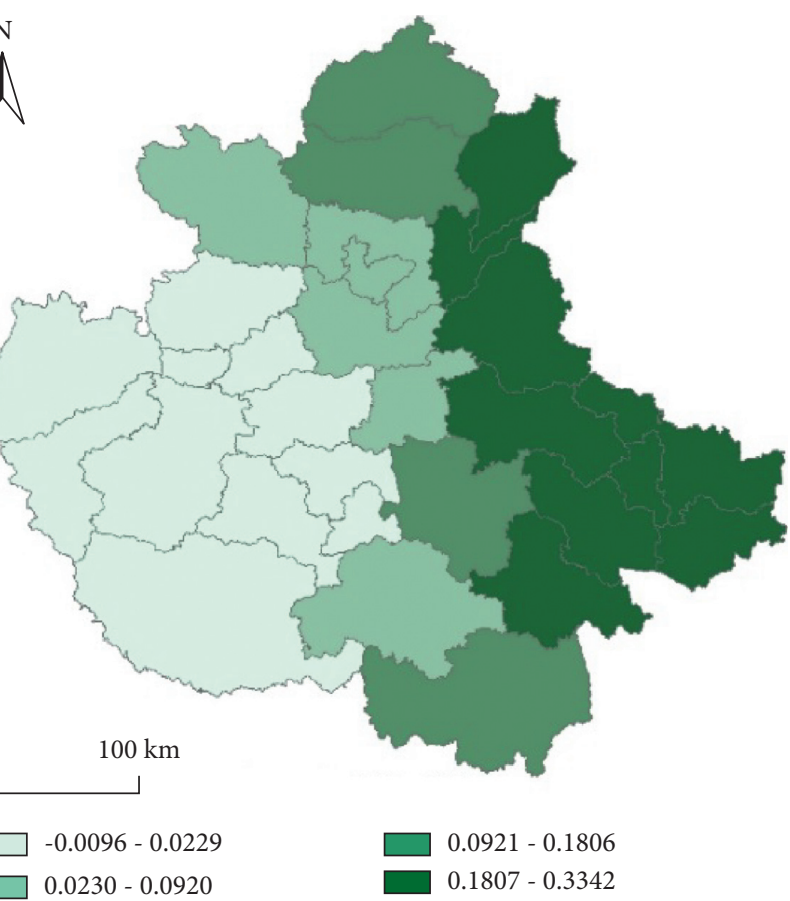

(c)

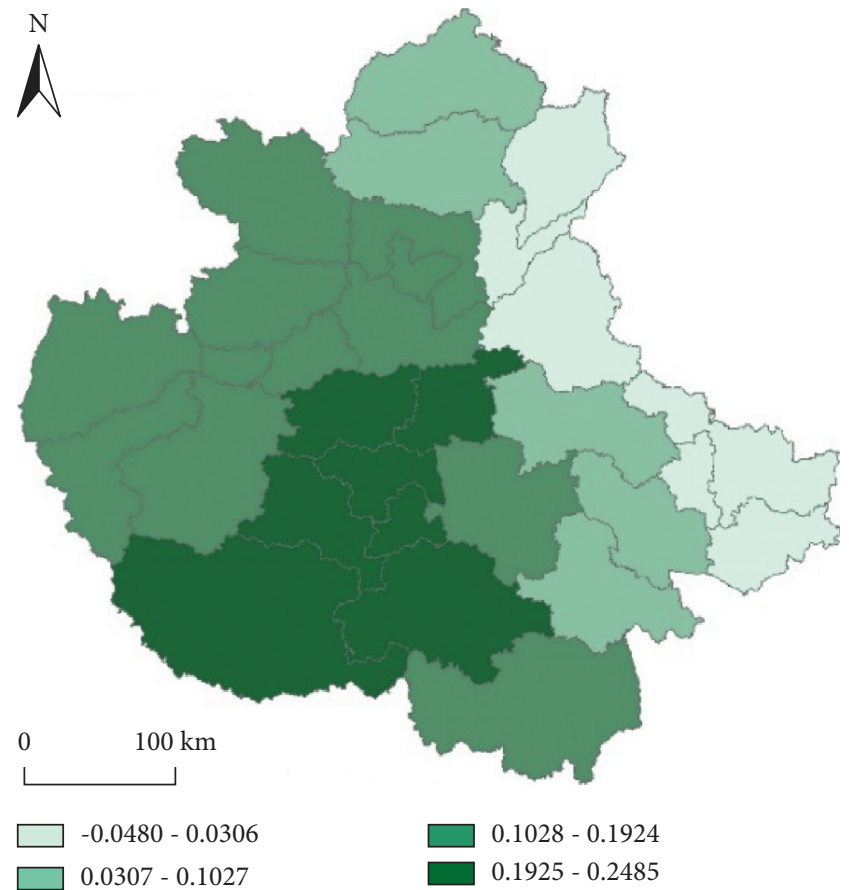

(b)

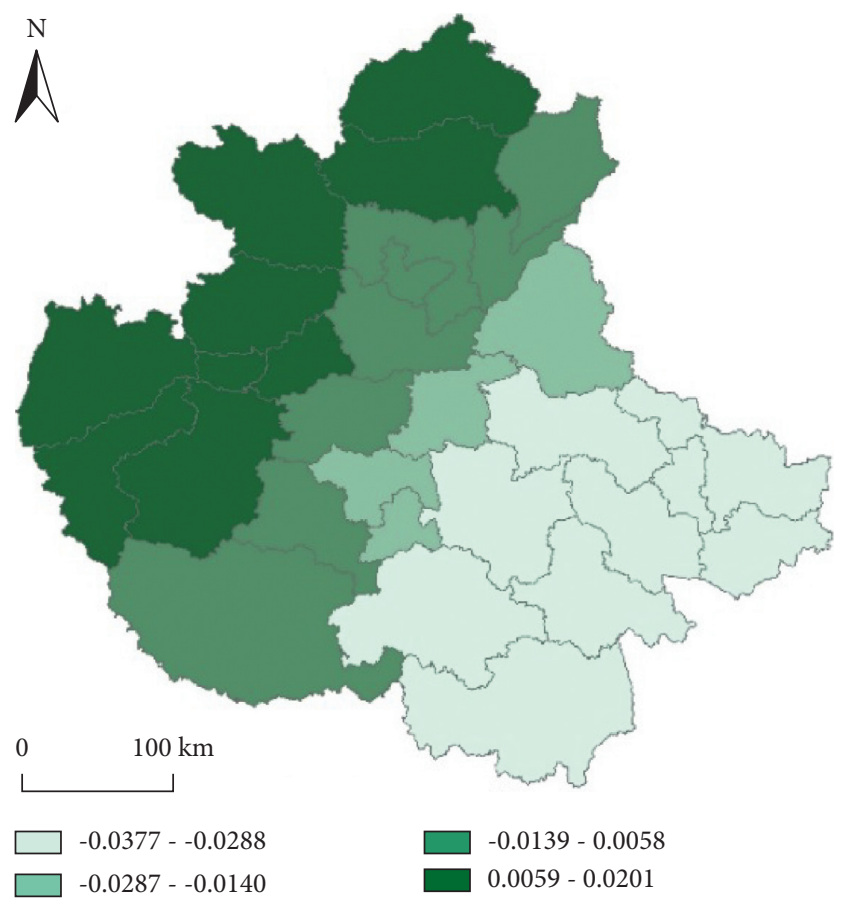

(d)

FIGURE 5: Spatial distribution of regression coefficients of each influencing factor. 
services and promote the transformation of the local logistics industry into an advanced productive service industry, which has a significant positive effect on the total factor productivity of the logistics industry. The areas with low regression coefficients are mainly concentrated, in the northeastern part of the Central Plains urban agglomeration. Although the development of education can have a positive effect on the coordinated development of logistics industry and economy, the promotion effect is not significant. The development of education can have a less significant positive effect on the coordinated development of logistics industry and economy. In conclusion, on the one hand, the talent resources of each city are not efficiently allocated and their potential is not fully developed; on the other hand, under the background of siphon which is brought by Zhengzhou, one of the provincial capitals, and big cities such as Beijing, Shanghai, and Guangzhou, a lot of high-end technical and managerial talents loss seriously from the seven cities mentioned above.

(3) As shown in Figure 5, the level of science and technology has a positive influence on the coupled development of logistics industry and economy in the Central Plains urban agglomeration. The regression coefficients range from 0.0620 to 0.3132 , indicating that the level of science and technology has an important driving role in the evolution of the coupled and coordinated development of the two systems. Spatially, it also shows a hierarchical bandlike spatial pattern decreasing from southeast to northwest. The western belt in the area of high value of regression coefficient is a demonstration area of innovation development in the Central Plains urban agglomeration. They have a good institutional environment, which is beneficial to improve the efficiency of $R \& D$ fund utilization and accelerate the transformation of $\mathrm{R} \& \mathrm{D}$ inputs into scientific and technological achievements. In addition, the transportation system between cities in the southwest zone is well developed, which provides convenient conditions for the circulation of various scientific research results between regions and promotes the development of various industries in the direction of high quality, leading to the continuous improvement of the coupling and coordination relationship between logistics industry and economy. The area with low value of regression coefficient is mainly concentrated in the eleven cities of Jincheng, Jiaozuo, Zhengzhou, Xuchang, Luohe, Nanyang, Pingdingshan, Luoyang, Sanmenxia, Yuncheng, and Jiyuan, which are located at the junction of Henan, Shandong, and Hebei provinces, and the inter-regional knowledge and technology exchange are hindered under the border effect, the collaborative innovation capacity of the five cities is low, and the knowledge spillover effect is not strong, coupled with the fact that the R\&D funding from input to output results and marketization has a lagging effect, so the driving effect of science and technology level on the coordinated development of logistics industry and economy is not obvious.

(4) As shown in Figure 5, population density has a significant effect on the coupled development of logistics industry and economy in the Central Plains urban agglomeration. The regression coefficient ranges from -0.1971 to 0.0842 . Spatially, it shows a hierarchical band-like spatial pattern decreasing from northwest to southeast. The areas with high absolute values of regression coefficients are mainly concentrated in Xingtai, Handan, Changzhi, Jincheng, Jiyuan, Zhengzhou, Luoyang, Sanmenxia, and Yuncheng in the northwest zone. Generally speaking, the higher the population density, the better the concentration of production factors and the generation of scale economy effect, but when the urban disease brought about by the population density is too high, it will hinder the economic development. The industries in Xingtai, Handan, Changzhi, Jincheng, Jiyuan, Zhengzhou, Luoyang, Sanmenxia, and Yuncheng are mostly population-intensive industries, and the positive externalities and spatial agglomeration effects generated by population concentration are weakened by the "border effect," resulting in the "crowding effect" being greater than the "agglomeration effect"; consequently, urban ecological and land resources become scarce, exceeding the carrying capacity of the city, and urban operation costs increase instead of decrease, resulting in insufficient economic development momentum. In the southeastern zone of the low absolute value of the regression coefficient, against the background of the gradual weakening of the demographic dividend, the overcrowding effect caused by the overcrowding of these cities is greater than the scale effect, and the traffic congestion caused by the high population density and the overloading of infrastructure increases the costs of logistics enterprises in terms of transportation and time, leading to the hindrance of the development of the logistics industry.

\section{Conclusions}

6.1. Research Implications. This paper takes 30 prefecturelevel cities in the Central Plains City Cluster as the research unit; the spatial pattern and spatial correlation characteristics of the coupling and coordination degree between logistics industry and economy are studied with the help of ArcGIS10.3 software. Then, the influential factors affecting the coordinated development of the two systems are investigated by using the GWR model, and the main research findings are as follows: 
(1) The comprehensive development level of logistics industry and economy in the Central Plains urban agglomeration is low, and there are significant differences in development between regions. Compared with $\mathrm{Mu}$ and Wang et al. [76] the research conclusion on the coupled development of logistics industry in Xinjiang, the overall development level is continuously optimized, but the coupling coordination degree is not high and presents spatial heterogeneity, just like the cities in Central Plains. Among them, Urumqi, the provincial capital city, is second to none in terms of coupling and coordinated development level. Similarly, Zhengzhou, the central city in the Central Plains City Cluster, is also the "only" with great development level.

(2) The overall coupling and coordination degree of logistics industry and economy in Central Plains urban agglomeration is not high, and it is in the stage of imminent disorder. Spatially, it shows a spatial pattern of "high in the center, low in the surroundings." Compared with the conclusion of Gao and Wang et al. [63] the study on the Pearl River Delta, the coupling coordination degree of the pan-Pearl River Delta region presents an inverted " $U$ " shape from the temporal perspective, there is hierarchical heterogeneity in the coupling coordination degree from the spatial perspective, and the "Matthew effect" is obvious. Area of more than $80 \%$ of the province of economy and the coupling coordination degree has very obvious spatial locking and path dependence, the overall development of the Central Plains city of coupling coordinationlevel higher areas is mainly distributed in the Central Plains urban agglomeration between the north and the south, low coupling coordinationlevel regions is "a group of three points" on the space pattern of distribution, "one group" mainly refers to the cluster area in the southeast of the urban agglomeration, and "two points" mainly refers to Yuncheng, Puyang, Xingtai, and other cities.

(3) From the global spatial autocorrelation, the coupling and coordination degree of each city is strongly positively spatially correlated, with significant clustering. From the local spatial autocorrelation, the spatial heterogeneity of the cold and hot spots of the coupling coordination degree of the two systems is obvious, with the hot spot areas clustered and distributed in the central and western parts; the secondary hot spot areas are distributed in a circular pattern around the hot spot areas with a few scattered in the southeast; the secondary cold spot areas are distributed and scattered in the northeast, southwest, and southeast; the cold spot areas are clustered in the southeast.

(4) Increasing urbanization rate has a positive effect on the coupled development of logistics industry and economy in the Central Plains urban agglomeration, while educational development and science and technology levels largely show positive effects, while population density has a more significant negative effect. Spatially, the urbanization rate shows a band pattern decreasing from southwest to northeast, the driving effect of education level shows a band distribution decreasing from southwest to northeast, the level of science and technology shows a band pattern decreasing from east to west, and the inhibitory effect of population density on each city shows an increasing trend from northwest to southeast. In terms of the mean values of the regression coefficients, the degree of influence is urbanization rate $>$ science and technology level $>$ education level $>$ population density.

6.2. Practical Implications and Managerial Insights. The above empirical analysis shows that the logistics industry and the economy of the Central Plains urban agglomeration influence each other and interact with each other, and the logistics industry can promote the economic development to a certain extent, while the economic growth has a supporting and pulling effect on the logistics industry. In addition, urbanization rate, educational development level, science and technology level, population density, and other factors have a significant impact on the coupled and coordinated development of the two systems and in view of this paper put forward the following policy recommendations.

(1) Strengthen the construction of weak links and promote the development of modern logistics industry. Firstly, the logistics transportation network and communication infrastructure construction of Central Plains city group should be established to improve the infrastructure construction of logistics industry, break the barrier of poor communication between provincial and municipal regions and information, and realize the compatibility of information linkage between regions and transportation modes. Secondly, we need to encourage universities and scientific research institutions to open logisticsrelated disciplines, strengthen the training of logistics professionals by providing specialized training for existing logistics personnel, popularize the basic points of logistics knowledge, break the technical difficulties of logistics, and achieve continuous improvement in the specialization of the logistics industry. Finally, to increase government support, the governments of prefecture-level cities jointly can develop a strategic development plan for the logistics industry in the Central Plains City Cluster, standardize the financing market, create a good financing environment for logistics enterprises, what else, through tax incentives, financial support, and other measures to cultivate leading logistics enterprises, and support small and medium-sized logistics enterprises, and bigger and stronger special logistics enterprises. 
(2) Coordinate regional development and promote high-quality economic development. Firstly, we should create a favorable external environment, provide guarantee for industrial transformation and upgrading, and encourage enterprises to increase investment in technology research and development, thus upgrading traditional industries, accelerating the cultivation of new industries, and promoting economic quality and efficiency. Secondly, improve the resource integration and synergy mechanism among cities within the Central Plains City Cluster, give full play to the government's macrocontrol role, reasonably guide the flow of resources among various regions and industries, and focus on enhancing regional development momentum. Finally, we should rationalize the layout and strengthen the intercity connection, such as put western part of the Central Plains Urban as a highland of development, and the spatial radiation and driving effect to other cities should be improved; the southwest part of the city should give full play to its resource advantages and promote the transformation and upgrading of traditional industries and the development of new industries; the northeast part of the cities should strengthen the crossregional coordinated development, break the influence of the "cut-change effect," and enhance the intercity resource factor flow. The southeast should take advantage of the "cost depression" to promote the generation of new growth poles of economic development and drive the development of traditional industries by "leading the surface with a point."

(3) Adapt to local conditions and diversify the drive. First, it should continue to promote urbanization, break through the boundaries of municipalities, provide a broader market space for the development of logistics industry, and drive the demand for logistics by releasing the consumption potential of residents, stimulating the vitality of industries, promoting trade exchanges, and enhancing economic efficiency. Secondly, it should promote internal development while increasing the investment in education, optimize education structure, promote the docking of university disciplines with local industries, focus on cultivating specialized talents, and accelerate the establishment of an integrated innovation mechanism of industry-university research. Again, when the government increases R\&D investment and encourages enterprises to increase their research expenses, it should improve the efficiency of R\&D fund utilization by improving relevant systems and systems, and decide the R\&D investment structure according to regional development characteristics. Finally, the government should promote the development of cities in the direction of intensification and reasonably channel the population flow in each region in order to reduce the inhibiting effect of population density on the coordinated development of logistics industry and economy.

\section{Data Availability}

The data used to support the findings of this study are available from the corresponding author upon request.

\section{Conflicts of Interest}

The authors declare that there are no conflicts of interest.

\section{Acknowledgments}

This work was financially supported by the following projects: the National Social Science Foundation of China (grant no. 19FGLB062), the Major Fundamental Research Programme of Philosophy and Social Science in Henan Higher Education Institutions (grant no. 2021-JCZD-25), the Henan Province Philosophy and Social Science Planning Programme (grant no. 2020CZH012), and the Think-tank Programme of Henan Science \& Technology (grant no. HNKJZK-2022-07B).

\section{References}

[1] Y. He, F. Zhou, M. Qi, and X. Wang, "Joint distribution: service paradigm, key technologies and its application in the context of Chinese express industry," International Journal of Logistics Research and Applications, vol. 23, no. 3, pp. 211-227, 2020.

[2] F. Zhou, Y. He, P. Ma, and R. V. Mahto, "Knowledge management practice of medical cloud logistics industry: transportation resource semantic discovery based on ontology modelling," Journal of Intellectual Capital, vol. 22, no. 2, pp. 360-383, 2021.

[3] S. Choudhary, R. Nayak, M. Dora, N. Mishra, and A. Ghadge, "SI-TBL: an integrated lean and green approach for improving sustainability performance: a case study of a packaging manufacturing SME in the UK," Production Planning \& Control, vol. 30, no. 5-6, pp. 353-368, 2019.

[4] P. K. Dey, C. Malesios, D. De, S. Chowdhury, and F. B. Abdelaziz, "Could lean practices and process innovation enhance supply chain sustainability of small and mediumsized enterprises?" Business Strategy and the Environment, vol. 28, no. 4, pp. 582-598, 2019.

[5] V. Duque-Uribe, W. Sarache, and E. V. Gutierrez, "Sustainable supply chain management practices and sustainable performance in hospitals: a systematic review and integrative framework," Sustainability, vol. 11, no. 21, p. 30, 2019.

[6] S. Treven, D. Uršič, and W. Rashad, "How management tools holistically support enterprises' operation in supply chains?" Management, vol. 24, no. 1, pp. 1-20, 2019.

[7] A. Kucharcikova and M. Miciak, "The application of human capital efficiency management towards the increase of performance and competitiveness in an enterprise operating in the field of distribution logistics," Nase More, vol. 65, no. 4, pp. 276-283, 2018. 
[8] P. V. Popov and I. Y. Miretskij, "Methodology for constructing the region's logistics infrastructure," Economy of Region, vol. 15, no. 2, pp. 483-492, 2019.

[9] M. N. Shaik and W. Abdul-Kader, "Comprehensive performance measurement and causal-effect decision making model for reverse logistics enterprise," Computers \& Industrial Engineering, vol. 68, pp. 87-103, 2014.

[10] M. N. Shaik and W. Abdul-Kader, "A hybrid multiple criteria decision making approach for measuring comprehensive performance of reverse logistics enterprises," Computers \& Industrial Engineering, vol. 123, pp. 9-25, 2018.

[11] K. Saparovna Mukhtarova, S. Sarsengalievich Ospanov, A. Antoni, and M. Duzbaievna Sharapiyeva, "The evaluation of the efficiency of transport and logistics infrastructure of railway transport," Pomorstvo: Scientific Journal of Maritime Research, vol. 32, no. 1, pp. 88-101, 2018.

[12] K. Hu, X. Q. Gan, and K. Gao, "Co-integration model of logistics infrastructure investment and regional economic growth in Central China," in Proceedings of the International Conference on Medical Physics and Biomedical Engineering (ICMPBE), pp. 1036-1041, Elsevier Science Bv, Qingdao, CHINA, September 2010.

[13] Z. Raimbekov, B. Syzdykbayeva, A. Baimbetova, and Z. Rakhmetulina, "Evaluating the impact of logistics infrastructure on the functioning and development of regional economy," Econ Ann-XXI, vol. 160, no. 7-8, pp. 100-104, 2016.

[14] Z. Zhang, "Current situation, problems and Countermeasures of green supply chain in China," Environmental Protection, vol. 47, no. 07 , pp. 49-52, 2019.

[15] r Cao and j Rui, "Influence of manufacturing agglomeration on spatial evolution of logistics industry: taking jiangsu province as an example," Areal Research and Development, vol. 38, no. 02, pp. 44-49, 2019.

[16] $\mathrm{m}$ Liu, $\mathrm{m}$ Zhai, and $\mathrm{x}$ Chen, "Decision-making of transnational green supply chain from the perspectives of tariff and subsidy," Soft Science, vol. 33, no. 09, pp. 21-26, 2019.

[17] h Tian, y Cui, and y Jiang, "Can green supply chain management improve corporate sustainable development?" Collected Essays on Finance and Economics, vol. 10, pp. 77-85, 2018.

[18] M. N. Vazifehdan and S. A. Darestani, "Green logistics outsourcing employing multi criteria decision making and quality function deployment in the petrochemical industry (vol 35, pg 243, 2019)," Asian J Shipping Logist, vol. 37, no. 2, p. 210, 2021.

[19] F. Zhou, X. Wang, M. K. Lim, Y. He, and L. Li, "Sustainable recycling partner selection using fuzzy DEMATEL-AEWFVIKOR: a case study in small-and-medium enterprises (SMEs)," Journal of Cleaner Production, vol. 196, pp. 489-504, 2018.

[20] z Wang, "Evaluating the efficiency of the interactive development between China's manufacturing and logistics industry [J]," China Business And Market, vol. 31, no. 02, pp. 20-30, 2017.

[21] C. X. Q. Sainan, "Research on coordinated development of China's logistics and financial industry based on coupling coordination degree and grey relational analysis," Journal of Industrial Technological Economics, vol. 38, no. 07, pp. 93-100, 2019.

[22] d Song and y Liu, "Study on harmonious development of industry growth stage and logistics strategy managementtaking China green food industry as an example," China Soft Science, vol. 01, pp. 49-55+87, 2008.
[23] S. X. Yang, J. F. Xu, and R. Y. Yang, "Research on coordination and driving factors of sports industry and regional sustainable development-empirical research based on panel data of provinces and cities in eastern China," Sustainability, vol. 12, no. 3 , p. $21,2020$.

[24] F. Zhou, G. Wang, T. Chen, P. Ma, and S. Pratap, "Regional leading industry selection based on an extended fuzzy VIKOR approach," International Journal of Decision Support System Technology, vol. 14, no. 1, 2022.

[25] S. Agrawal, R. K. Singh, and Q. Murtaza, "A literature review and perspectives in reverse logistics," Resources, Conservation and Recycling, vol. 97, pp. 76-92, 2015.

[26] A. Münter and K. Volgmann, "The metropolization and regionalization of the knowledge economy in the multi-core rhine-ruhr metropolitan region," European Planning Studies, vol. 22, no. 12, pp. 2542-2560, 2014.

[27] W. Zhang, X. Zhang, M. Zhang, and W. Li, "How to coordinate economic, logistics and ecological environment? Evidences from 30 provinces and cities in China," Sustainability, vol. 12, no. 3, 2020.

[28] P. Klaus, "Logistics research: a 50 years' march of ideas," Logistics Research, vol. 1, no. 1, pp. 53-65, 2009.

[29] Y. F. Li and C. L. Fan, "Logistics system planning based on industrial supply chain-yunnan province as example," in Proceedings of the International Conference on Management, Manufacturing and Materials Engineering (ICMMM 2011), p. 796, Trans Tech Publications Ltd, Zhengzhou, CHINA, January 2011.

[30] F. Zhou, M. K. Lim, Y. He, and S. Pratap, "What attracts vehicle consumers' buying," Industrial Management \& Data Systems, vol. 120, no. 1, pp. 57-78, 2019.

[31] F. Zhou, Y. He, and L. Zhou, "Last mile delivery with stochastic travel times considering dual services," IEEE Access, vol. 7, Article ID 159013, 2019.

[32] F. Zhou and Y. He, "Research on pallet scheduling model with time windows and uncertain transportation time," Engineering Letters, vol. 28, no. 2, pp. 504-509, 2020.

[33] F. Zhou and Y. He, "Pallet scheduling models under deterministic and non-deterministic scenarios using a hybrid ga method," International Journal of Decision Support System Technology, vol. 13, no. 2, pp. 1-15, 2021.

[34] F. Zhou, M. K. Lim, Y. He, Y. Lin, and S. Chen, "End-of-life vehicle (ELV) recycling management: improving performance using an ISM approach," Journal of Cleaner Production, vol. 228, pp. 231-243, 2019.

[35] C. Lindsey, H. S. Mahmassani, M. Mullarkey, T. Nash, and S. Rothberg, "Regional logistics hubs, freight activity and industrial space demand: econometric analysis," Research in Transportation Business \& Management, vol. 11, pp. 98-104, 2014.

[36] F. Zhou, X. Wang, M. Goh, L. Zhou, and Y. He, "Supplier portfolio of key outsourcing parts selection using a two-stage decision making framework for Chinese domestic automaker," Computers \& Industrial Engineering, vol. 128, pp. 559-575, 2019.

[37] F. Zhou, Y. He, P. Ma, M. K. Lim, and S. Pratap, "Capacitated disassembly scheduling with random demand and operation time," Journal of the Operational Reserach Society, 2021, in Press.

[38] F. Zhou, P. Ma, Y. He, S. Pratap, P. Yu, and B. Yang, "Lean production of ship-pipe parts based on lot-sizing optimization and PFB control strategy," Kybernetes, vol. 50, no. 5, pp. 1483-1505, 2021. 
[39] J. P. Cohen, "The broader effects of transportation infrastructure: spatial econometrics and productivity approaches," Transportation Research Part E: Logistics and Transportation Review, vol. 46, no. 3, pp. 317-326, 2010.

[40] X. Shu, Y. Gao, Y. Zhang, and C. Yang, "Study on the coupling relationship and coordinative development between tourism industry and eco-civilization city," China Population, Resources and Environment, vol. 25, no. 03, pp. 82-90, 2015.

[41] L. Zhao, L. Li, and Y. Wu, "Research on the coupling coordination of a sea-land system based on an integrated approach and new evaluation index system: a case study in hainan province, China," Sustainability, vol. 9, no. 5, 2017.

[42] M. Tomal, "Evaluation of coupling coordination degree and convergence behaviour of local development: A spatiotemporal analysis of all Polish municipalities over the period 2003-2019," Sustainable Cities and Society, vol. 71, 2021.

[43] S. Dong, J. Zheng, Y. Li et al., "Quantitative analysis of the coupling coordination degree between urbanization and ecoenvironment in Mongolia," Chinese Geographical Science, vol. 29, no. 5, pp. 861-871, 2019.

[44] W. Bao, Y. Yang, and L. Zou, "How to reconcile land use conflicts in mega urban agglomeration? A scenario-based study in the Beijing-Tianjin-Hebei region, China," Journal of Environmental Management, vol. 296, Article ID 113168, 2021.

[45] L. Guo and A. Farouk, "Coupling coordination degree between new urbanization and eco-environment in shaanxi, China, and its influencing factors," Discrete Dynamics in Nature and Society, vol. 2021, pp. 1-8, 2021.

[46] H. Han, H. Li, and K. Zhang, "Spatial-temporal coupling analysis of the coordination between urbanization and water ecosystem in the yangtze river economic belt," International Journal of Environmental Research and Public Health, vol. 16, no. 19, 2019.

[47] R. Qiao, H. Li, and H. Han, "Spatio-temporal coupling coordination analysis between urbanization and water resource carrying capacity of the provinces in the yellow river basin, China," Water, vol. 13, no. 3, 2021.

[48] X. Cheng, R. Long, H. Chen, and Q. Li, "Coupling coordination degree and spatial dynamic evolution of a regional green competitiveness system - a case study from China," Ecological Indicators, vol. 104, pp. 489-500, 2019.

[49] Y. Guo and W. Qiao, "Rural migration and urbanization in China: historical evolution and coupling pattern," Sustainability, vol. 12, no. 18, 2020.

[50] H. Liu, B. Huang, and C. Yang, "Assessing the coordination between economic growth and urban climate change in China from 2000 to 2015," The Science of the Total Environment, vol. 732, Article ID 139283, 2020.

[51] F. Ren and X. Yu, "Coupling analysis of urbanization and ecological total factor energy efficiency - - a case study from Hebei province in China," Sustainable Cities and Society, vol. 74, 2021.

[52] Y. Tian, D. Zhou, and G. Jiang, "Conflict or coordination? multiscale assessment of the spatio-temporal coupling relationship between urbanization and ecosystem services: the case of the Jingjinji Region, China," Ecol Indic, vol. 117, 2020.

[53] X. Wang and D. Liu, "The coupling coordination relationship between tourism competitiveness and economic growth of developing countries," Sustainability, vol. 12, no. 6, 2020.

[54] L. Zhang, M. Wu, W. Bai, Y. Jin, M. Yu, and J. Ren, "Measuring coupling coordination between urban economic development and air quality based on the Fuzzy BWM and improved CCD model," Sustainable Cities and Society, vol. 75, 2021.

[55] L. Duan, F. Deng, S. Jia, Q. Gong, and A. Z. Abdullah, "Regional Agriculture Coupling Coordination Analysis Based on Sustainable Development: A Case Study of Sichuan, China," E3S Web of Conferences, vol. 245, 2021.

[56] J. Huang, J. Shen, and L. Miao, "Carbon emissions trading and sustainable development in China: empirical analysis based on the coupling coordination degree model," International Journal of Environmental Research and Public Health, vol. 18, no. 1,2020

[57] L. Liu, Y. Zhang, J. Zhang, and S. Zhang, "Coupling coordination degree of government support, financial support and innovation and its impact on economic development," IEEE ACCESS, vol. 8, Article ID 104039, 2020.

[58] d Wang and $\mathrm{x} \mathrm{Lu}$, "On Chinese tourim innovation ability based on improved coupling coordination model-A case study of interprovincial panel data of 2008-2017," Journal of South China Normal University (Social Science Edition), vol. 45, no. 08, pp. 77-86, 2020.

[59] Z. Zhang and Y. Li, "Coupling coordination and spatiotemporal dynamic evolution between urbanization and geological hazards-A case study from China," The Science of the Total Environment, p. 728, Article ID 138825, 2020.

[60] y Zhao and h Lv, "Coupling mechanism of new urbanization and agricultural modernization in China," Journal of Capital University of Economics and Business, vol. 18, no. 03, pp. 3-10, 2016.

[61] C. Hou, H. Chen, and R. Long, "Coupling and coordination of China's economy, ecological environment and health from a green production perspective," International journal of Environmental Science and Technology, vol. 20, 2021.

[62] Y. Yang, R. Wang, J. Tan, and J. L. Calvo-Rolle, "Coupling coordination and prediction research of tourism industry development and ecological environment in China," Discrete Dynamics in Nature and Society, vol. 2021, pp. 1-15, 2021.

[63] k Gao, m Wang, and b Zhang, "Coupling synergy evolution and spatial difference of pan-Pearl River Delta regional economy and logistics," Prices Monthly, vol. 09, pp. 49-55, 2018.

[64] Q. Qin, Z. L. Hu, A. L. Liu, Y. Huang, and F. T. Zhang, "Identification and evolution of the noncoordination coupling relationship between tourism poverty alleviation and ecological environments in poor mountainous areas," Discrete Dynamics in Nature and Society, pp. 2020-14, Article ID 5094863, 2020.

[65] L. Jun, "Research on the coordination development between the logistics industry and the regional economy--mechanism analysis and empirical research," Journal of Industrial Technologyical Economics, vol. 36, no. 07, pp. 78-82, 2017.

[66] C. Zhi-guo, C. Jian, and D. Jin-hua, "Study on coupling coordination development between logistics industry and national economy in China - - an empirical analysis based on provincial panel data," China Business And Market, vol. 34, no. 01, pp. 9-20, 2020.

[67] Y. S. Shi, D. H. Shi, and X. Y. Cao, "Impacting factors and temporal and spatial differentiation of land subsidence in Shanghai," Sustainability, vol. 10, no. 9, p. 18, 2018.

[68] k Gao, z Zhou, and y Yang, "Land use structure and its spatial autocorrelation analysis in the yangtze river basin," Resources and Environment in the Yangtze Basin, vol. 19, no. S1, pp. 13-20, 2010. 
[69] x Xue and b Fan, "Analysis on temporal and spatial evolution in production distribution of dairy cow farming in China," Chinese Journal of Animal Science, vol. 55, no. 11, pp. 174-179, 2019.

[70] w Guan, x Peng, h Zhang, and y Wei, "Reginal economic inequalities in jiangsu at differrent spatial scales," Resources and Environment in the Yangtze Basin, vol. 24, no. 12, pp. 2003-2011, 2015.

[71] x Zhou, h Yang, and y Zhao, "Study on coupling evaluation and spatial analysis of regional economy and logistics development in silk road economic belt," Railway Transport and Economy, vol. 39, no. 01, pp. 13-17+28, 2017.

[72] b Ca, w Zhao, y Li, and z Li, "Spatial pattern and influencing factors of coupling coordination degree between regional innovation and regional economy in China," Science and Technology Management Research, vol. 39, no. 09, pp. 96-105, 2019.

[73] Z. Gan, T. Feng, M. Yang, H. Timmermans, and J. Luo, "Analysis of metro station ridership considering spatial heterogeneity," Chinese Geographical Science, vol. 29, no. 6, pp. 1065-1077, 2019.

[74] Y. Rouphael, A. H. Mouneimne, A. Ismail, E. Gyves, C. M. Rivera, and G. Colla, "Modeling individual leaf area of rose (Rosa hybrida L.) based on leaf length and width measurement," Photosynthetica, vol. 48, no. 1, pp. 9-15, 2010.

[75] A. M. Bazaz, Z. K. Fariman, and M. Bannayan, "Modeling individual leaf area of basil (Ocimum basilicum) using different methods," International Journal of Plant Production, vol. 5, no. 4, pp. 439-447, 2011.

[76] $\mathrm{x} \mathrm{Mu,} 1$ Wang, and q Huang, "A probe into the high-quality development path of logistics industry based on coupling coordination degree model - - - taking Xinjiang as an example," Prices Monthly, vol. 12, pp. 55-63, 2019. 